\title{
Effect of Fading on Performance of VANET in Realistic Scenarios Using NCTUns6.0
}

\author{
Richa Sharma ${ }^{1}$, Jyoteesh Malhotra ${ }^{2}$ and Komal Sharma ${ }^{3}$ \\ ${ }^{1}$ CSE Department, G.N.D.U R.C, Jalandhar, India, Rixs11111991@gmail.com \\ ${ }^{2}$ H.O.D of C.S.E and E.C.E Department, G.N.D.U R.C, Jalandhar India \\ ${ }^{3}$ ECE Department, G.N.D.U R.C, Jalandhar, India \\ Rixs11111991@gmail.com,jyoteesh@gmail.com,komal.10ece@gmail.com
}

\begin{abstract}
Road safety and increasing transport efficiency are the important goals for intelligent transport system (ITS). Vehicular Ad hoc Network is such a network which can help to achieve these goals. VANET routing is a crucial task for reliable communication among vehicles. The impact of fading on network throughput and packet drop is explored in this paper. Interesting results show the performance evaluation of without fading environment and Rayleigh fading in different scenarios. NCTUns 6.0 (National Chiao Tung University Network Simulator) is used to justify our results that is a GUI based open source platform for vehicular Ad-Hoc network. Various performance issues are also surveyed with the help of this simulator.
\end{abstract}

Keywords: VANET, Fading, NCTUns6.0, Packet drop, Throughput.

\section{Introduction.}

With the continuous increase in the number of vehicle on roads, people[1] are facing serious problem of traffic congestion, which give rise to Vehicular Ad-hoc Networks System in which vehicles can communicate with other vehicles using dedicated short range radio signals DSRC $(5.9 \mathrm{GHz})$ standard that employs the IEEE $802.11 \mathrm{p}$ for wireless communication. As to simulate a powerful ITS network NCTUns 6.0 provides a solution to simulate IEEE 802.11(p) vehicular network. This simulator helps to integrate the simulations of a road network and a communication network. The 802.11(p) standard is divided into two network nodes namely 802.11(p) On Board Unit(OBU) which is equipped with a DSRC radio and 802.11(p) Road Side Unit which is connected with a DSRC radio mounted on road sides. Also RSUs are installed on both sides of roads at several $\mathrm{km}$ apart (usually after every $1 \mathrm{~km}$ apart). These RSU are connected to different network devices and act as router between them. OBUs are installed on each and every vehicle which is responsible for the communication between the vehicle and RSU via DSRC radio signals. VANET provides applications like safety, comfort and multimedia applications. Safety applications include alerting the driver to slow down its speed by conveying information about the occurring of accident, condition of road, road turn, traffic light etc. Comfort application includes the online information about the parking lot, petrol stations, map while entering a new city. It also includes toll payment by recharging the OBU installed in every car, while passing the car through toll tax station. The amount of tax can be automatically deducted. Thus, it can save time and traffic congestion can be minimized. In this paper we try to find the effect of fading on performance of VANET on two scenarios with help of NCTUns-6.0 simulator. In the II section what is fading and its effect is discussed. Further aims and objectives are outlined. In the III section we use NCTUns-6.0 simulation tool. In the IV section related work done has been described. Various performance evaluation using fading is listed in related work section. In the last section the paper is concluded. 


\section{Effect of Fading}

Fading in wireless means deviation of the attenuation which is affecting a signal over a particular propagation media. It may vary with frequency, position and time. Fading may be either due to multipath propagation or due to shadowing from obstacles. Fading is characterized in two types namely slow fading and fast fading. Fast fading is due to multipath propagation of transmitted signals. As multiple paths most of the times add either constructively or destructively at the receiver side which leads to variation in power level. If there is one line of sight path between sender and receiver then it follows ricean distribution and it follows Rayleigh distribution when there is no such path between the two[7]. Later in this paper comparison of performance of Rayleigh and without fading channel is discussed using NCTUns 6.0.

\subsection{Aims and Objectives}

Aim of this paper is to identify effect of Rayleigh fading on performance parameters of VANET. Parameters like throughput and packet drop are used for comparison with ideal situation and realistic situation in which fading is included in VANET. On the basis of comparison we will be able to suggest effect of fading on performance parameters in city and highway scenario of VANET.

\section{Research Methodology Used}

"Simulation is the technique of solving problems by analyzing the performance in virtual environment of a model also known as simulator [16]. Simulation development is iterative process in which the construction, execution and analysis of a model repeatedly perform in order to achieve desired level of understandings [17].

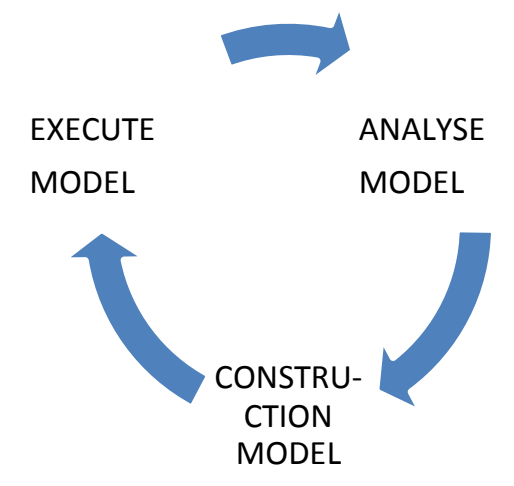

Figure 1. A Simulation Process

\subsection{Simulation Tool}

In this study we use GUI based integrated traffic simulation network known as NCTUNs (National Chiao Tung University Network Simulator)[18]. This simulator provides simulation in network protocol, road network, vehicular traffic and various feedback paths between them. NCTUns is open source platform for vehicular ad hoc network. NCTUns has Linux operating system which supports Red-Hat Fedora 11 with 2.6.28.9 Linux kernel version. It supports both wired and wireless network. The language behind its coding is $\mathrm{C}++$. In this simulator packets are passed through Linux based TCP/IP protocol stack. Some features of NCTUNs are as follows:

- High -Fidelity Results

- Use real-life application programs 
- Can be turned into emulator

- Repeatable and faster simulation results

- Highly integrated GUI environment

- Provides maximum support to important networks.

\subsection{Performance Parameters}

Performance of various routing protocols can be compared based on the two parameters namely Throughput and Packet Drop as follows.

1. Throughput

Throughput is described as the total number of packets received at destination out of total packets transmitted. Throughput is measured in bytes/sec.

2. Packets Drop

Packet drop shows the total number packets dropped i.e not successfully received at destination. The protocol performance increases with fall in packet drop.

3. Collision Rate

Collision rate can be defined as number of packets collides per second. It should be less for better performance.

\subsection{NCTUns-6.0}

Although NCTUns-6.0 provides highly GUI environment and less programming overhead, despite of this, it also has some limitations. NCTUns-6.0 provides only single TCP/IP version, where as mostly network simulators provide multiple TCP/IP versions inside a single simulator. Inside single simulation NCTUns-6.0 can support maximum of 4096 nodes while other traffic simulators like TRANS can support more nodes inside a single simulation (bullet list).

\section{Related Work}

\subsection{Simulation Scenario}

A city scenario and highway scenario are considered here having different number of nodes(vehicles) and speed. The scenario is drawn with "draw topology" feature of NCTUns-6.0 simulator. In these scenarios we have used 802.11(p) OBU equipped with DSRC radio. A icon marked with a is a agent controlled 802.11(p) OBU. In this OBU to control moving behaviour and message delivery is done by real life car agent programs.

\section{Table1. Simulation Parameters for RSU-OBU Scenario}

\begin{tabular}{|l|l|}
\hline PARAMETERS & VALUE \\
\hline Data rate & $6 \mathrm{mbps}$ \\
\hline Transmit power & $28.8 \mathrm{dbm}$ \\
\hline Receiver sensitivity & $-82.0 \mathrm{dpm}$ \\
\hline Fading variance & 10 \\
\hline Average building height & 10.0 \\
\hline Average building distance & 80.0 \\
\hline Street width & 30.0 \\
\hline Path loss exponent & 2.0 \\
\hline Shadowing standard deviation & 4.0 \\
\hline System loss & 1.0 \\
\hline Antenna height & 1.5 \\
\hline Path loss model & Two way ground \\
\hline
\end{tabular}




\section{Case1. City Scenario}

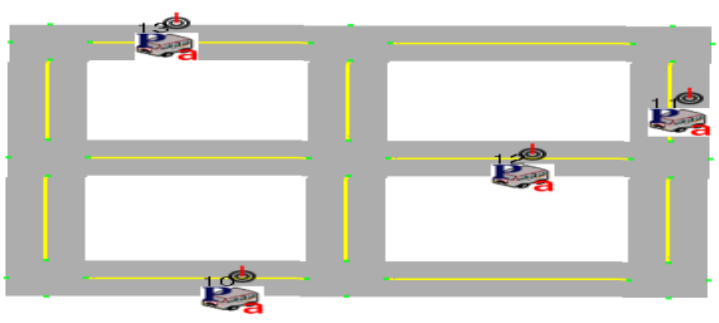

Figure 2. City Scenario Case having 4 Nodes and $10 \mathrm{~m} / \mathrm{s}$ Speed Drawn Using NCTUns-6.0 Simulator

\section{Case 2. Highway Scenario}

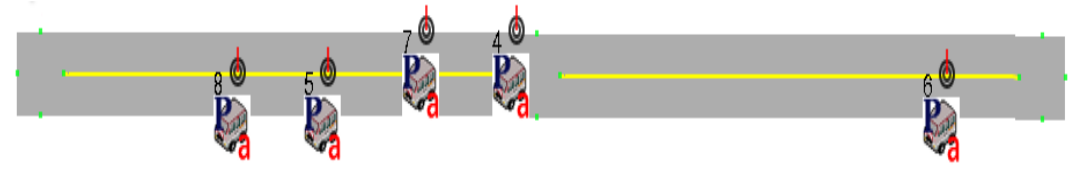

\section{Figure 3. Highway Scenario Case with 5 Nodes and 10m/s Speed Drawn} Using NCTUns-6.0

\subsection{Simulation Result}

The graph listed below shows the performance of UDP protocols in both the scenarios. These graphs are based on following the performance parameters:

- $\quad$ Throughput

- $\quad$ Packet drop rate

- $\quad$ Collision rate

Here Different QOS parameters for VANET have been compared for ideal case and for real life scenario. For example RF stands for Rayleigh Fading while none shows without fading effect as given below.

\section{Case 1 City Scenario}

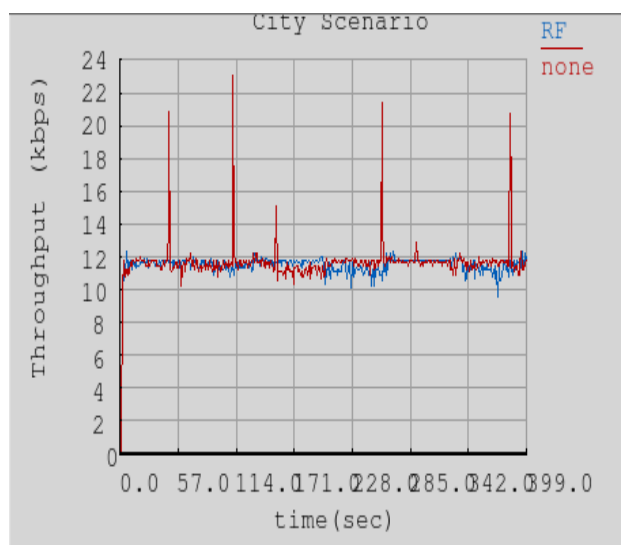

Figure 4. Effect of Throughput in City Scenario 


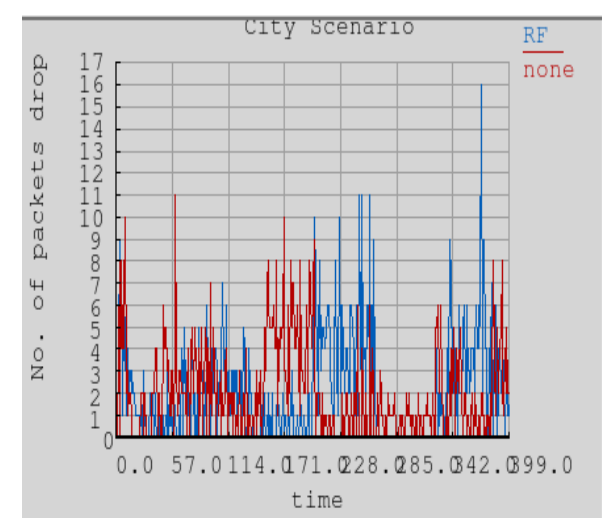

Figure 5. Effect of Packet Drop Rate in City Scenario

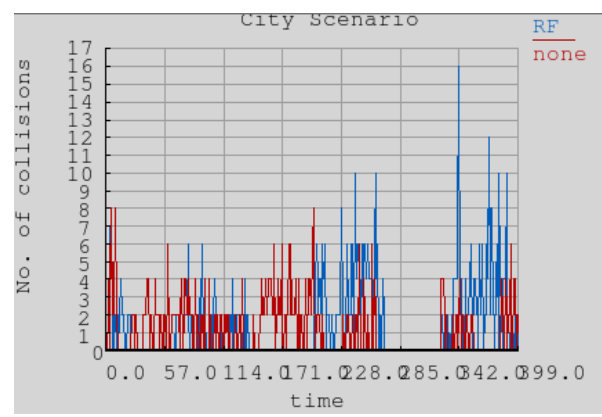

Figure 6. Effect of Number of Collision in City Scenario

Case 2 Highway scenario

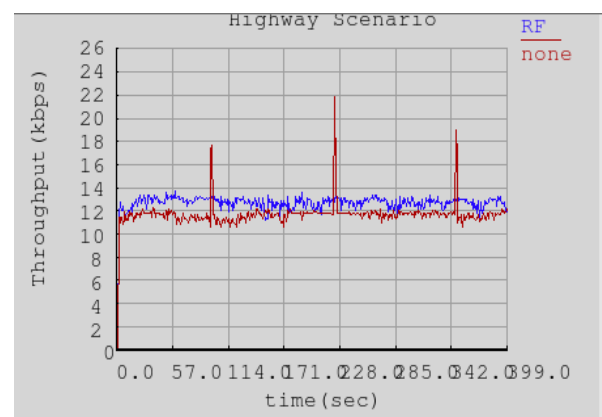

Figure 7. Throughput Performance for Highway Scenario

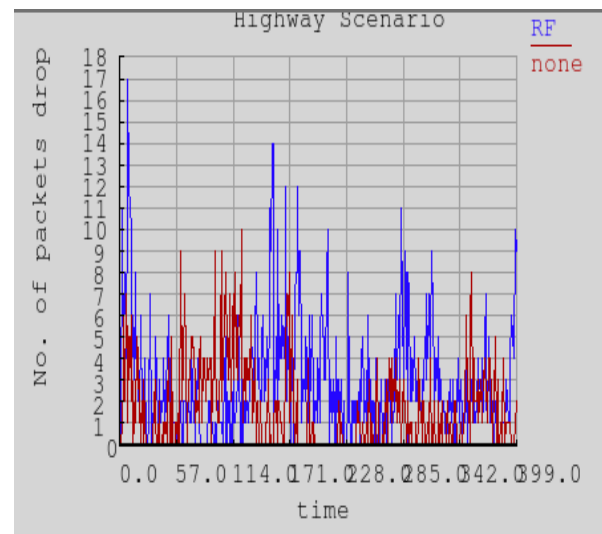

Figure 8. Effect of Packet Drop Rate in Highway Scenario 


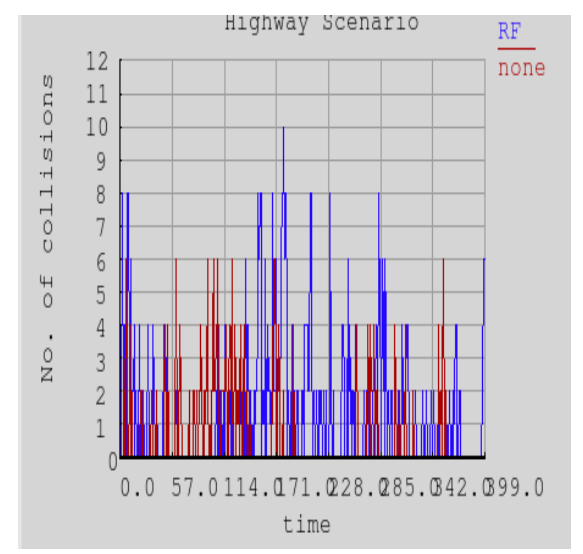

Figure 9. Effect of Number of Collision in Highway Scenario

The quality of service parameters (throughput and packet drop) has been evaluated at two different time intervals i.e at $33 \mathrm{sec}$ and $77 \mathrm{sec}$, for city and highway scenario and has been provided in tabular form as given below.

\section{Case 1 for City Scenario}

Table 2. Performance Evaluation of Number of Packet Drop in City Scenario

\begin{tabular}{|l|l|l|}
\hline $\begin{array}{l}\text { No. of packets } \\
\text { drop }\end{array}$ & $\begin{array}{l}\text { Maximum } \\
\text { value }\end{array}$ & $\begin{array}{l}\text { Minimum } \\
\text { value }\end{array}$ \\
\hline $\begin{array}{l}\text { Rayleigh } \\
\text { fading }\end{array}$ & 16 & 2 \\
\hline $\begin{array}{l}\text { Without } \\
\text { fading }\end{array}$ & 11 & 1 \\
\hline
\end{tabular}

Table 3. Throughput Evaluation in City Scenario

\begin{tabular}{|l|l|l|}
\hline $\begin{array}{l}\text { Throughput } \\
\text { (kbps) }\end{array}$ & $\begin{array}{l}\text { Maximum } \\
\text { value }\end{array}$ & $\begin{array}{l}\text { Minimum } \\
\text { value }\end{array}$ \\
\hline $\begin{array}{l}\text { Rayleigh } \\
\text { fading }\end{array}$ & 13 & 9 \\
\hline $\begin{array}{l}\text { Without } \\
\text { fading }\end{array}$ & 22 & 11 \\
\hline
\end{tabular}

Table 4. Values of Number of Collision in City Scenario

\begin{tabular}{|l|l|l|}
\hline $\begin{array}{l}\text { No. of } \\
\text { collisions }\end{array}$ & $\begin{array}{l}\text { Maximum } \\
\text { value }\end{array}$ & $\begin{array}{l}\text { Minimum } \\
\text { value }\end{array}$ \\
\hline $\begin{array}{l}\text { Rayleigh } \\
\text { fading }\end{array}$ & 16 & 4 \\
\hline $\begin{array}{l}\text { Without } \\
\text { fading }\end{array}$ & 8 & 2 \\
\hline
\end{tabular}




\section{Case 2. For Highway Scenario}

\section{Table 5. Performance Evaluation of Number of Packet Drop in Highway} Scenario

\begin{tabular}{|l|l|l|}
\hline $\begin{array}{l}\text { No. of } \\
\text { packets drop }\end{array}$ & $\begin{array}{l}\text { Maximum } \\
\text { value }\end{array}$ & $\begin{array}{l}\text { Minimum } \\
\text { value }\end{array}$ \\
\hline $\begin{array}{l}\text { Rayleigh } \\
\text { fading }\end{array}$ & 17 & 3 \\
\hline $\begin{array}{l}\text { Without } \\
\text { fading }\end{array}$ & 10 & 2 \\
\hline
\end{tabular}

Table 6. Throughput Evaluation in Highway Scenario

\begin{tabular}{|l|l|l|}
\hline $\begin{array}{l}\text { Throughput } \\
\text { (kbps) }\end{array}$ & $\begin{array}{l}\text { Maximum } \\
\text { value }\end{array}$ & $\begin{array}{l}\text { Minimum } \\
\text { value }\end{array}$ \\
\hline $\begin{array}{l}\text { Rayleigh } \\
\text { fading }\end{array}$ & 14 & 11 \\
\hline $\begin{array}{l}\text { Without } \\
\text { fading }\end{array}$ & 23 & 11 \\
\hline
\end{tabular}

Table 7. Values of Number of Collision in Highway Scenario

\begin{tabular}{|l|l|l|}
\hline $\begin{array}{l}\text { No. of } \\
\text { collisions }\end{array}$ & $\begin{array}{l}\text { Maximum } \\
\text { value }\end{array}$ & $\begin{array}{l}\text { Minimum } \\
\text { value }\end{array}$ \\
\hline $\begin{array}{l}\text { Rayleigh } \\
\text { fading }\end{array}$ & 10 & 2 \\
\hline $\begin{array}{l}\text { Without } \\
\text { fading }\end{array}$ & 6 & 1 \\
\hline
\end{tabular}

It can be analyzed from the table that throughput ratio decreases with the effect of fading while number of collisions and number of packets drop per second increases as we include the effect of fading. It has also been examined that number of collisions per second in city scenario is more than highway scenario while throughput ratio of city scenario is less than the highway scenario. This is due to the congestion due to traffic in the city scenario the collision rate of city scenario increases thus the packet drop rate also gets increases and thus throughput ratio gets increases.

\section{Conclusion}

The main goal of this paper is to find different parameters which affect the performance of VANET and to evaluate its quality of service parameters (throughput, collision rate and packet drop ratio) in city as well as highway scenario. It can be used as reference for the active researchers in this field. In this paper different QOS parameters for VANET without fading effect and with introducing the effect of Rayleigh fading in VANET has been examined. It has been found that quality of service in city scenario is less than highway scenario and effect of fading will lead to increase the packet drop ratio 
and thus throughput ratio will be further decreased. The performance issues regarding path connectivity and time delay should be improved. It is hoped that this paper will provide guidelines for active researchers working on QOS parameters in the VANET.

\section{Acknowledgement}

We are very thankful to Almighty God; whose grace and blessed mercy enabled me to complete this work with full devotion. We are also grateful to Dr. Jyoteesh Malhotra, Head of the Department, Department of CSE and ECE Department, GNDU RC Jalandhar, for their invaluable support and guidance throughout this research work. We are also thankful to our families and all those who helped us in one way or other at every stage of my work.

\section{References}

[1] Pawan Dahiya, Prachi Choudhary and Kusum Dalal, IJCS, vol. 36, (2011), pp. 6-9.

[2] The GUI based User Manual for the NCTUns 6.0 Network Simulator.

[3] H. Hartenstein, K. Laberteaux, "VANET Vehicular Applications and Inter-Networking Technologies", (2010), pp.472.

[4] J. Nzouonta, N. Rajgure, G. Wang and Cristian Borcea, "VANET Routing on City Roads Using RealTime Vehicular Traffic Information", IEEE Transactions on Vehicular Technology, vol. 58, no 7, (2009).

[5] J. Zhao and G. Cao, "VADD: vehicle-assisted data delivery in vehicular Ad Hoc networks," Proceedings of the 25th IEEE International Conference on Computer Communications (INFOCOM '06), (2006); Barcelona, Spain.

[6] C. Cooper, F. Safai, A. Mukantan and D. Franklin, "Studying the impact of the corner propagation model on VANET routing in urban environments", IEEE Vehicular Technology Conference, (2012).

[7] Y. R. Zheng, C. Xiao and N. C. Beaulieu, "Statistical simulation models for Rayleigh and Rican fading", IEEE International Conference on Communication, vol. 5, (2003).

[8] S.R.Das, R. Castaneda and R. Sengupta, "Comparative performance evaluation of routing protocols for mobile ad hoc networks", 7th Int. Conf. on (IC3N), (2010), vol. 4, no. 2, pp 120-127.

[9] Y. Toor, P. Muhlethaler and I. A. Laouiti, "Vehicle Ad Hoc Networks: Applications and Related Technical Issues", IEEE Transactions On Vehicular Technology, (2012), vol. 10, no. 3.

[10] S.Y. Wang and H.T. Kung, "A Simple Methodology for Constructing Extensible and High Fidelity TCP/IP Network Simulator”, IEEE INFOCOM'99, (1999); New York, USA. 